\title{
EFFECT OF CURING TEMPERATURE IN THE ALKALI-ACTIVATED BLAST-FURNACE SLAG PASTE AND THEIR STRUCTURAL INFLUENCE OF POROSITY
}

\section{Teresita de Jesús Medina-Serna', Susana Paola Arredondo-Rea', José Manuel Gómez-Soberón², Carlos Antonio Rosas-Casarez ${ }^{1}$, Ramón Corral-Higuera ${ }^{1}$}

\footnotetext{
1 Facultad de Ingeniería Mochis, Universidad Autónoma de Sinaloa, Los Mochis, Sinaloa, Mexico, e-mail: teresita. medina@uas.edu.mx; paola.arredondo@uas.edu.mx; carlos.arc@uas.edu.mx; ramon.corral@uas.edu.mx

2 Departamento de Construcciones Arquitectónicas II, Universidad Politécnica de Cataluña, EPSEB, Barcelona, Spain, e-mail: josemanuel.gomez@upc.edu
}

Received: 2016.06.21

Accepted: 2016.07.14

Published: 2016.09.01

\begin{abstract}
Due to the environmental problem posed by the use of Portland cement as construction material, it becomes necessary the search for supplementary cementitious materials that mitigate the ecological damage caused by it. Because the chemical similarity and the high cementitious powers of the blast furnace slag, it is used in the generation of geopolymers in a cement total replacement. This research focused on the study of the influence of the curing conditions on the final properties of blast furnace slag establishing three variables: no cured process $(\mathrm{N}-\mathrm{C})$, cured of controlled temperature of $45^{\circ} \mathrm{C}(\mathrm{CT} 45-\mathrm{C})$ and room temperature cure (RT-C); evaluating the mechanical behavior until 28 days of age and the water porosity index. The results show that geopolymers based on blast furnace slag has a behavior similar to hydration maturity of Portland cement and curing process decreases the porosity; On the other hand, applying a controlled temperature generates densest resistant pastes such as the variable CT45-C which reach the highest value of resistance in all curing ages.
\end{abstract}

Keywords: activation of geopolymers, alternative materials, concrete friendly, curing temperature, maturation of hydration.

\section{INTRODUCTION}

Globalization and the constant development of countries require the application of new and improved infrastructure to meet the needs and requirements, but without commit the resources of future generations. Portland cement (PC) is essential to address these needs as it is imperative in concrete, material which by their strength, durability and versatility, its the most used in construction industry; however, energy associated with the manufacture of cement tends to overcome $1700 \mathrm{MJ}$ per Ton produced, releasing thus to the atmosphere a Ton of $\mathrm{CO}_{2}[1,2]$. On the other hand, it is attributed to this gas the order of $65 \%$ of global warming, which, PC manufactur- ing is responsible for over $75 \%$ of total emissions. About 3.6 billion Ton of cement are produced annually in the world [3, 4], therefore it is necessary to search for new alternative materials with low energy requirements in production; so that, they achieve to mitigate the negative effects of their use on the environment.

Because the blast furnace slag (BFS) has a similar chemical composition to the PC, this it is being used as a new supplementary cementitious material (SCM) for its ability to produce the celled geopolymers (CG), which are able to achieve high performance of resistance and durability $[2,5]$. Hydration process of BFS starts with the formation of an aluminosilicate "Shell" on the surface of the slag grains. This shell is 
impermeable to water and does not allow additional hydration until it is broken or dissolved. Since the reactive components of BFS are aluminosilicates of calcium and magnesium, these because of their $\mathrm{pH}$, they can only be dissolved in high alkaline media [6-8], thus being necessary the use of activators to participate in the cation exchange and act as reaction catalysts. The most effective activating substances, from the perspective of obtaining good mechanical behavior in $\mathrm{CG}$, are sodium hydroxide $(\mathrm{NaOH})$ and sodium silicate $\left(\mathrm{Na}_{2} \mathrm{O}_{3} \mathrm{Si}\right)$ [5, 9].

In 1964 industrial production of SCM began, and from the 80 's has been investigated its partial replacement in the cement, taking special interest its composition and hydraulic behavior in the 90's and stating that the main reaction product of alkaline activation of BFS is a hydrated calcium silicate gel with aluminum in the structure (CASH); to which the desirables mechanical properties are attributed [9-12]. The chemical composition of BFS is also vital in alkali activation and in the formation of hydration products. The content of aluminum oxide $\left(\mathrm{Al}_{2} \mathrm{O}_{3}\right)$ helps greater reactivity at an early age and improves compressive strength; likewise the content of magnesium oxide $(\mathrm{MgO})$, which decreases porosity and increases strength [13, 14].

Although it has considerably studied the mechanisms controlling the alkali activation, the nature of the slag and the characteristics of the reaction products, it is necessary to establish the influence of other parameters such as curing conditions on the final properties of the geopolymer. According to this, the present research has evaluated the influence of the curing temperature in factors such as porosity and consequent mechanical properties in geopolymer pastes based on BFS activated with $\mathrm{NaOH}$ and $\mathrm{Na}_{2} \mathrm{O}_{3} \mathrm{Si}$.

\section{MATERIALS}

The BFS used in this study, was provided by Altos Hornos de México, S.A.B. de C.V. which is located in Monclova, Coahuila $\left(26^{\circ} 53^{\prime} 08.5^{\prime} \mathrm{N}\right.$ $\left.101^{\circ} 27^{\prime} 10.0^{\prime \prime} \mathrm{W}\right)$. It was obtained from a process of thermal foundry and rapid cooling with water. The chemical composition was examined using an X-ray fluorescence (XRF) by a FRX SRS3000 spectrometer (Table 1). The main compound of $\mathrm{BFS}$ is $\mathrm{CaO}$, which classifies them as hydraulic, acording to the classification of Escalante Garcia (2002) [15] and therefore, they are suitable for possible use as cement substitute material.

The BFS was supplied with an average particle size of the order of $0.37 \mathrm{~mm}$, which were subjected to a size reduction process by grinding in sequences of $500 \mathrm{~g}$ in a rotating ball mill with 19 balls of $540 \mathrm{~g}$ each and during a period of 2 hours. The result of milling was then sectioned by sieving (sieve 45 $\mu \mathrm{m}$ ASTM E11-95 [16]), and for research was used the fraction passing the sieve, since it is assumed it will have a greater surface area and thus it will improve their eventual hydration process. The particle size distributions of the BFS were estimated using laser granulometry by a Mastersizer 2000 (Figure 1). Particle sizes range from 0.4 to $100 \mu \mathrm{m}$, with $38 \%$ of $0.4-10$ $\mu \mathrm{m}, 55 \%$ of $10-45 \mu \mathrm{m}$ and $7 \%$ of particles larger than $45 \mu \mathrm{m}$. Based on these results it is estimate that fineness of BFS corresponds with allowable limits in sieving and it is an optimal finesse to achieve maximum surface areas.

It was used sodium hydroxide $(\mathrm{NaOH})$ pellets containing sodium carbonate $\left(\mathrm{Na}_{2} \mathrm{CO}_{3}\right)$ in $1 \%$, they were dissolved in distilled water at a molarity of 8 , in order to obtain one of the two components of the alkaline activator for applying in BFS. Sodium silicate $\left(\mathrm{Na}_{2} \mathrm{O}_{3} \mathrm{Si}\right)$ solution with a modulus $\left(\mathrm{SiO}_{2} / \mathrm{Na}_{2} \mathrm{O}\right.$ ratio) of 2.8 was also used as the second component of the alkaline activator.

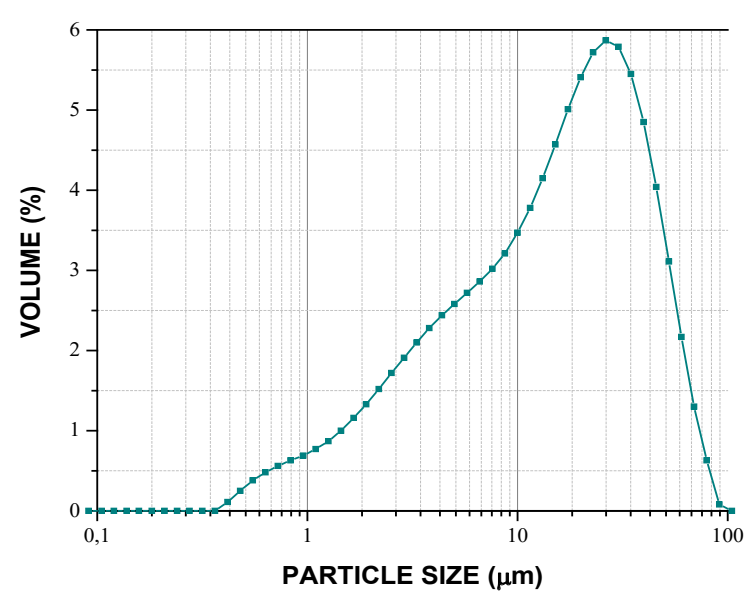

Fig. 1. Curve of particle size distribution of BFS

Table 1. Chemical composition of BFS in percentage (\%)

\begin{tabular}{|c|c|c|c|c|c|c|c|c|c|c|}
\hline $\mathrm{SiO}_{2}$ & $\mathrm{TiO}_{2}$ & $\mathrm{Al}_{2} \mathrm{O}_{3}$ & $\mathrm{Fe}_{2} \mathrm{O}_{3}$ & $\mathrm{MnO}$ & $\mathrm{MgO}$ & $\mathrm{CaO}$ & $\mathrm{Na}_{2} \mathrm{O}$ & $\mathrm{K}_{2} \mathrm{O}$ & $\mathrm{P}_{2} \mathrm{O}_{5}$ & Total \\
\hline 32.57 & 0.994 & 10.90 & 1.161 & 0.469 & 8.726 & 34.95 & 9.117 & 0.741 & 0.046 & 99.67 \\
\hline
\end{tabular}


Finally, distilled water with a $\mathrm{pH}$ between 6 and 7.5, total dissolved solids from 2 to $5 \mathrm{ppm}$ and without total hardness was used as solvent of $\mathrm{NaOH}$.

\section{METHODOLOGY}

\section{Sample preparation}

For the preparation of alkali activator (AA), a mixture of both reagents was used with a $\mathrm{NaOH} /$ $\mathrm{Na}_{2} \mathrm{O}_{3} \mathrm{Si}$ ratio of 0.72 , this composition was established in order to do not disturb the molarity and modulus of reagents.

Then, the AA was incorporated in BFS as required by the standard ASTM C-109 [17] (BFS/ AA ratio of 0.35 ). The preparation of the mixture was carried out manually in sequences of $150 \mathrm{~g}$ per batch, stirring until obtain adequate workability (1 minute approximately). Subsequent to mixing, were molded in $5 \times 5 \times 5 \mathrm{~cm}$ cubes, which were then subjected to a pre-cured treatment that consisted of subjecting them to a relative humidity of $100 \%$ (guaranteed by immersion bags and sealed with low density polyethylene to prevent loss of AA), with a temperature of $80^{\circ} \mathrm{C}$ and for a period of 24 hours, in order to accelerate the activation process of BFS.

Finally, a specimen was used as reference (N$\mathrm{C}$, zero days after pre-cured), the remaining half of $\mathrm{CG}$ were cured at a controlled temperature of $45^{\circ} \mathrm{C}$ (CT45-C) during 1, 3, 7, 14 and 28 days after pre-cured; And the rest of the specimens were subjected to cured at room temperature (RT-C) at identical test ages. When was necessary, as an experimental technique for stopping the process of hydration of the $\mathrm{CG}$, reached the curing age stipulated, acetone and alcohol baths were used in a ratio of 1 for a period of three days with daily replacement of solution [18].

\section{Characterization}

Standard test method for compressive strength (ASTM C109 [17]) was performed to all specimens of study at stipulated ages; and fractured fractions of this test were used to determinate the water porosity index (UNE-EN 1015-10 [19]).

The chemical composition of the BFL was examined using an X-ray fluorescence (XRF) spectrometer (PANalytical model X'Pert PRO). The sample was milled in a agate mortar until obtain a homogeneous fine powder, in order to orienting the crystals in all possible directions and subsequently was compressed until obtain a solid pill which was analyzed in a $2 \theta$ range of $4^{\circ}-90^{\circ}$, with a step size of 0.05 per second and in a time of 70 seconds by step, using a $\mathrm{CuK} \alpha$ radiation.

Scanning Electron Microscope (SEM) was performed on the JSM-6510 JEOL machine, with a resolution of $15 \mathrm{~nm}$ and a magnification of 200 $\mathrm{x}$. For this technique was necessary mounting resin and mechanical polishing of the samples.

\section{RESULTS AND DISCUSSION}

\section{The development of compressive strength}

The compressive testing results are presented in Figure 2. If we use as a reference N-C, the variable RT-C shows a decrease in resistance of $17.93 \%$; while that variable CT45-C reached a value of $47.56 \mathrm{MPa}(4.8 \%$ greater than N-C). From day old, both curves of the samples exhibit a normal and accelerated evolution of strength gain (hydration process similar to PC); that is, a rapid strength gain in the seven first days of curing, and from this moment, both curves have a slow or gradually strength-gain which it stabilizes at 28 days of age. Comparing the hydration process with respect to the maximum reached, in the age of seven days, CT45-C samples reached $95 \%$ and RT-C a 99\%, indicating that it reaches its resistance faster; though, in no case RT-C exceeds the resistance obtained by CT45-C samples, which reaches the maximum resistance of 52.37 $\mathrm{MPa}$. This suggests that the lack of temperature controlled in the curing process of CG causes decrease in compressive strength; this effect can be

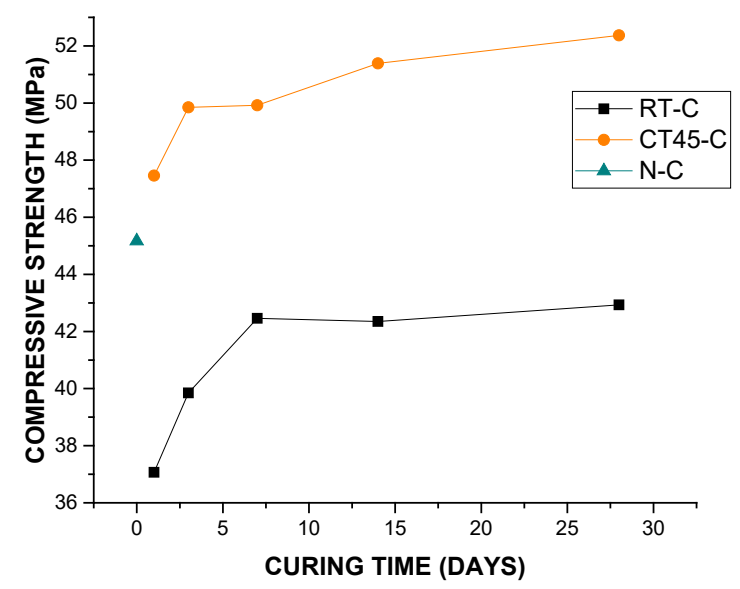

Fig. 2. Compressive strength of N-C, RT-C and CT45-C samples 

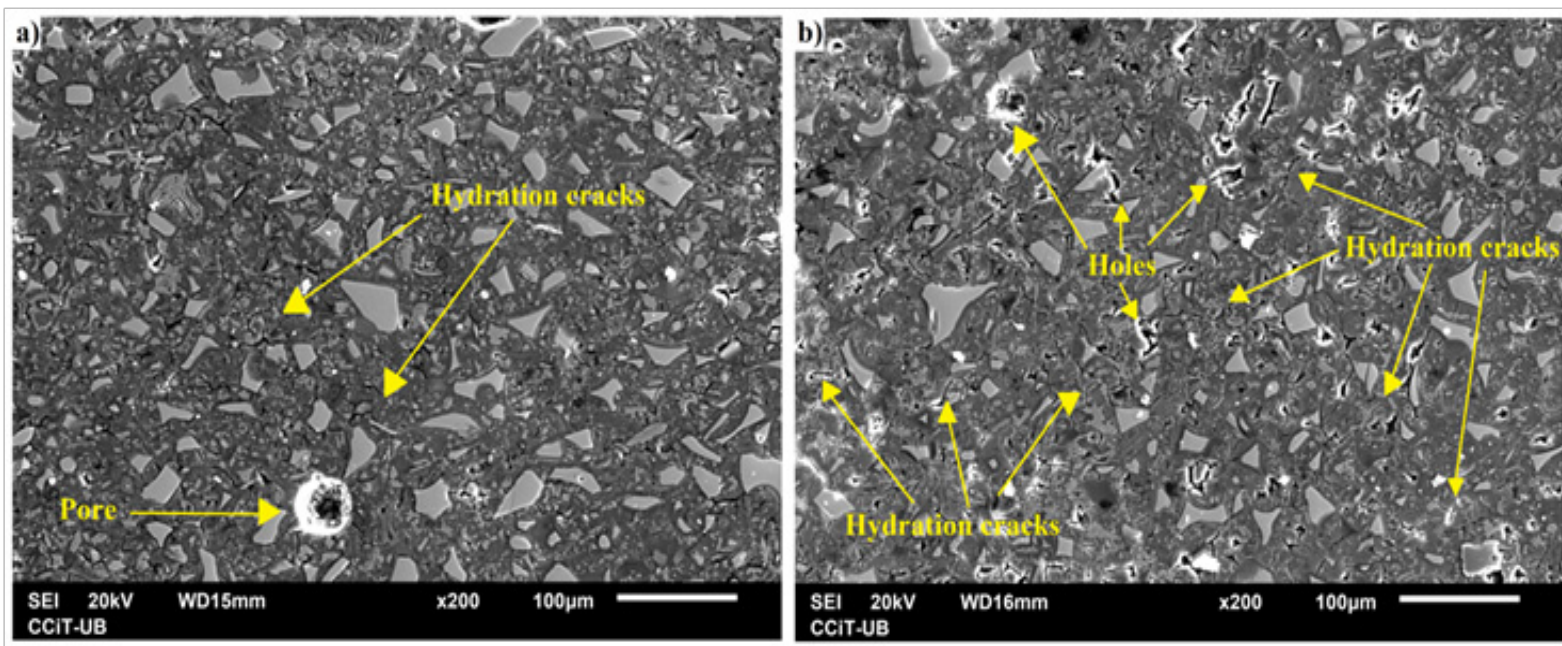

Fig. 3. SEM pictures for a CG with 3 days age a) CT45-C and b) RT-C

deduced by the images obtained by SEM (Figure 3 ), in them is appreciated that RT-C samples has microcracks, areas without the presence of compounds of hydration ("holes") and weak interfacial transition zone (not uniform or tortuous) with respect to the CT45-C samples, indicating that the first is less dense and resistant.

In the case of the CT45-C, the former behavior may be explained by the promoting effect of curing with temperature, which improves the hydration process of $\mathrm{CG}$ and therefore increases the formation of new compounds of hydration. As complementary technique of corroboration, XRD was performed on both samples at 7 days age; in Figure 4 and Table 2 can observe a decrease of the characteristic peaks of calcite in the CT45-C samples (present at the BFS source and which is consumed for the generation of reaction products) compared with the RT-C samples validating thus the previous hypothesis.

\section{Water porosity index}

In Figure 5 can be seen that N-C samples have a higher water porosity compared with CT45-C

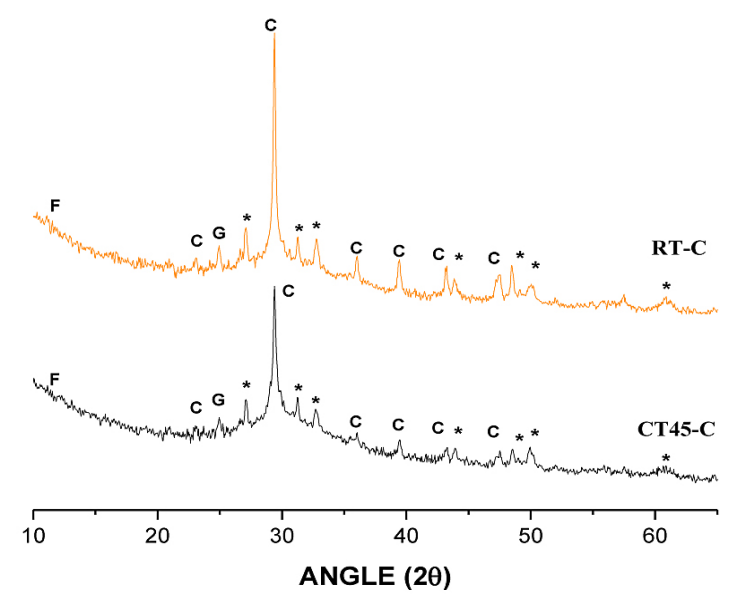

Fig. 4. XRD for CT45-C and RT-C at seven days age

and RT-C samples, showing that the curing process reduces the porosity of CG. On the other hand, when comparing both samples of study, RT-C has a lower porosity than CT45-C (behavior not expected according to previous analysis), though, the difference between the two is only $3.9 \%$, which is within the standard deviation of the test itself, indicating that the technique does not have a significant or appropriate sensitivity to the defection of them.

Table 2. Crystalline phases found in XRD

\begin{tabular}{|c|l|c|}
\hline & \multicolumn{1}{|c|}{ Phase Name } & Chemical Formula \\
\hline $\mathrm{C}$ & Calcium carbonate (Calcite) & $\mathrm{Ca}\left(\mathrm{CO}_{3}\right)$ \\
\hline $\mathrm{F}$ & Faujasite & $(\mathrm{Mg}, \mathrm{Na}, \mathrm{K}, \mathrm{Ca})_{\mathrm{n}}(\mathrm{Si}, \mathrm{Al})_{12} \mathrm{O}_{24}{ }_{25} \mathrm{H}_{2} \mathrm{O}$ \\
\hline $\mathrm{G}$ & Calcium silico aluminate (Gehlenite) & $\mathrm{Ca}_{2}\left(\mathrm{Al}(\mathrm{Al} \mathrm{Si}) \mathrm{O}_{7}\right.$ \\
\hline$*$ & & $\mathrm{CASH}-\mathrm{CSH}$ Phases \\
\hline & Tobermorite & $\mathrm{Ca}_{5} \mathrm{Si}_{6} \mathrm{O}_{16}(\mathrm{OH})_{2} \cdot \mathrm{nH}_{2} \mathrm{O}$ \\
\hline & Cebollite & $\mathrm{Ca}_{2}\left(\mathrm{Mg}, \mathrm{Fe}{ }^{+2}, \mathrm{Al}\right) \mathrm{Si}_{2}(\mathrm{O}, \mathrm{OH})_{7}$ \\
\hline & Melilite & $(\mathrm{Ca}, \mathrm{Na})_{2}(\mathrm{Al}, \mathrm{Mg})(\mathrm{Si}, \mathrm{Al})_{2} \mathrm{O}_{7}$ \\
\hline
\end{tabular}




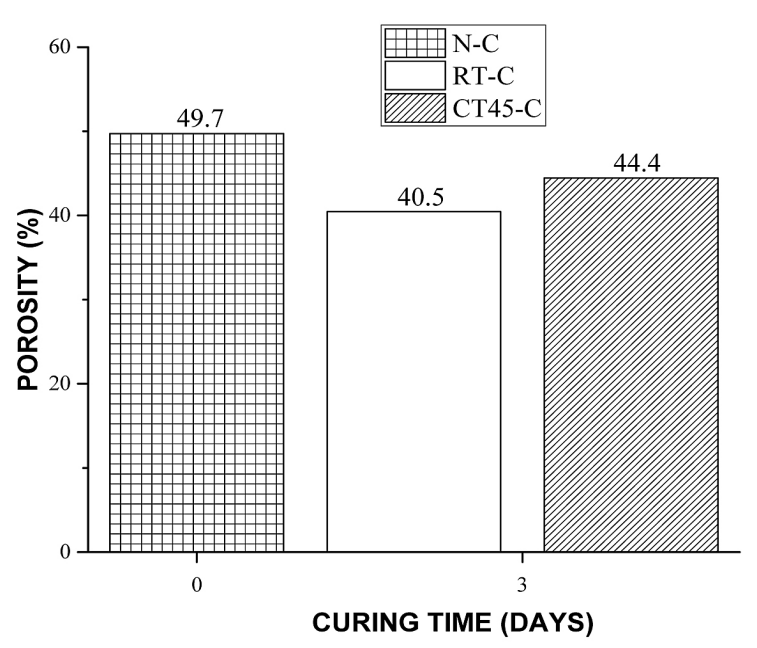

Fig. 5. Water porosity for N-C, RT-C and CT45-C

\section{CONCLUSIONS}

Creating an atmosphere with controlled temperature during the curing process improves the physical properties and mechanical performance of the CG, since the temperature is propulsive of the formation of compounds of hydration, which cause the generation of a dense paste with less micro-cracks and less holes in the matrix; furthermore also of stronger interfacial transition zones from lower thickness and better adhesion. All this, causes an increase in the compressive strength of the CG (16\%) when compared to the samples cured at ambient.

Independent of temperature, the CG based on BFS has a behavior on process of gain of resistance (maturity of hydration) similar to the PC, being even able to achieve greater compressive strength (52.37 MPa) at the age of 28 days.

Although the water porosity technique has no sufficient sensitivity for the correct determination of the porosity in studied pastas, it is possible to prove that the curing process reduces the porosity compared with those that were not subjected to this process.

The use of CG based BFS are a new alternative materials to $\mathrm{PC}$ which is more sustainable and even comparable o with higher performance, the forecast is that they are incorporated into construction industry to the extent of their use to the common welfare of the planet.

\section{Acknowledgements}

The authors express thanks to: research project S-01117 from CTT-UPC, to EPSEB-UPC, to the Department CAII-EPSEB-UPC, to FIM-UAS and to the scholarships program for Master Degree studies by CONACYT.

\section{REFERENCES}

1. Rashad A.M., A comprehensive overview about the influence of different admixtures and additives on the properties of alkali-activated fly ash. Mater. Des. 53, 2014, 1005-1025. DOI: 10.1016/j.matdes.2013.07.074.

2. Siddique R., Khan M.I., Supplementary Cementing Materials. Springer, 2011. DOI: 10.1017/ CBO9781107415324.004.

3. Flower D.J.M., Sanjayan J.G., Green house gas emissions due to concrete manufacture. Int. J. Life Cycle Assess. 12, 2007, 282-288. DOI: 10.1007/ s11367-007-0327-3.

4. Vera Martínez P.S., Análisis de las exportaciones mexicanas de cemento, 2001-2014. In: XX Congres Int. Contaduría, Adm. E Informática, Mexico, 2015.

5. Ben Haha, M. Le Saout G., Winnefeld F., Lothenbach B., Influence of activator type on hydration kinetics, hydrate assemblage and microstructural development of alkali activated blast-furnace slags. Cem. Concr. Res. 41, 2011, 301-310. DOI: 10.1016/j.cemconres.2010.11.016.

6. Gebregziabiher B.S., Thomas R., Peethamparan S. , Very early-age reaction kinetics and microstructural development in alkali-activated slag, Cem. Concr. Compos. 55, 2015, 91-102. DOI: 10.1016/j.cemconcomp.2014.09.001.

7. Espinoza L., Escalante I., Comparación de las propiedades del concreto utilizando escoria de alto horno como reemplazo parcial y total del cemento Pórtland ordinario, Nexo Rev. Científica. 21, 2008, 11-18.

8. Myers R.J., Lothenbach B., Bernal S.S., Provis J.L., Thermodynamic modelling of alkali-activated slag cements. Appl. Geochemistry. 61, 2015, $233-$ 247. DOI: 10.1016/j.apgeochem.2015.06.006.

9. Puertas F., Cementos de escorias activadas alcalinamente: Situación actual y perspectivas de futuro. Mater. Construcción. 45, 1995, 53-64. DOI: 10.3989/mc.1995.v45.i239.553.

10. Wang S.D., Scrivener K.L., Hydration products of alkali activated slag cement, Cem. Concr. Res. 25, 1995, 561-571. DOI: 10.1016/00088846(95)00045-E.

11. Zhang Y.J., Zhao Y.L., Li H.H., Xu D.L., Structure characterization of hydration products generated by alkaline activation of granulated blast furnace slag, J. Mater. Sci. 43, 2008, 7141-7147. DOI: 10.1007/s10853-008-3028-9.

12. Marjanovic N., Komljenovic M., Bascarevic Z., Nikolic V., Petrovic R., Physical-mechanical and 
microstructural properties of alkali-activated fly ash-blast furnace slag blends. Ceram. Int. 41, 2015, 1421-1435. DOI: 10.1016/j.ceramint.2014.09.075.

13. Ben Haha M., Lothenbach B., Le Saout G., Winnefeld F., Influence of slag chemistry on the hydration of alkali-activated blast-furnace slag - Part I: Effect of MgO. Cem. Concr. Res. 42, 2011, 74-83. DOI: 10.1016/j.cemconres.2011.08.005.

14. Ben Haha M., Lothenbach B., Le Saout G., Winnefeld F., Influence of slag chemistry on the hydration of alkali-activated blast-furnace slag - Part II: Effect of $\mathrm{Al}_{2} \mathrm{O}_{3}$. Cem. Concr. Res. 42, 2012, 74-83. DOI: 10.1016/j.cemconres.2011.08.005.

15. Escalante García J.I., Materiales alternativos al cemento Pórtland. Av. Y Perspect. 21, 2002, 79-88.

16. ASTM E11-95, Standard Specification for Wire Cloth and Sieves for Testing Purposes, West Con- shohocken, PA, 2001. DOI: 10.1520/E0011-95.

17. ASTM C109 / C109M-16a, Standard Test Method for Compressive Strength of Hydraulic Cement Mortars (Using 2-in. or [50-mm] Cube Specimens), West Conshohocken, 2016. DOI: 10.1520/ C0109_C0109M-16A.

18. Chen X., Meawad A., Struble L.J., Method to Stop Geopolymer Reaction, J. Am. Ceram. Soc. 6, 2014. n/a-n/a. DOI: 10.1111/jace.13071.

19. AENOR (Asociación Española de Normalización y Certificación), UNE-EN 1015-10:2000, Métodos de ensayo de los morteros para albañilería. Parte 10: Determinación de la densidad aparente en seco del mortero endurecido, 2000. http://www.aenor.es/aenor/normas/normas/ fichanorma.asp?tipo $=\mathrm{N} \& \operatorname{codigo}=\mathrm{N} 0022409 \#$. V2JzACPRjIV. 